\title{
A case of idiopathic diabetes insipidus presented with bilateral hydroureteronephrosis and neurogenic bladder: A pediatric case report and literature review
}

\author{
Ozgur Haki Yuksel, MD; Mithat Kivrak, MD; ${ }^{+}$Aytac Sahin, MD; ${ }^{*}$ Serkan Akan, MD; ${ }^{*}$ Ahmet Urkmez, MD; \\ Ayhan Verit, $M D^{*}$
}

*Fatih Sultan Mehmet Research and Training Hospital, Department of Urology, Içerenkoy/Atasehir, stanbul, Turkey; ${ }^{\dagger}$ Mus State Hospital, Mus, Turkey

Cite as: Can Urol Assoc J 2015;9(11-12):E817-20. http://dx.doi.org/10.5489/cuaj.3092 Published online November 4, 2015.

\section{Abstract}

Diabetes insipidus (DI) is a condition with heterogeneous clinical symptoms characterized by polyuria (urine output $>4 \mathrm{~mL} / \mathrm{kg} / \mathrm{hr}$ ) and polydipsia (water intake $>2 \mathrm{~L} / \mathrm{m}^{2} / \mathrm{d}$ ). In children, acquired nephrogenic DI (NDI) is more common than central DI (CDI). Diagnosis is based on the presence of high plasma osmolality and low urinary osmolality with significant water diuresis. A water deprivation test with vasopressin challenge, though has limitations, is done to differentiate NDI from CDI and diagnose their incomplete forms. Neonates and young infants are better managed with hydration therapy alone. Older children with CDI are treated with desmopressin (1-deamino-8- $D$-arginine vasopressin, dDAVP). Its oral form is safe, highly effective and has dosing flexibility. We report a case of an 8-year-old male patient with CDI with severe bilateral non-obstructive hydronephrosis and megaureter. Dramatic clinical and radiological responses to dDAVP treatment were achieved and therapy reduced urine volume and led to marked radiological improvement in hydronephrosis.

\section{Introduction}

Essential features of diabetes insipidus (DI) include: polyuria, defined as urine output of more than $4 \mathrm{~mL} / \mathrm{kg} / \mathrm{hr}$ in children (more than $6 \mathrm{~mL} / \mathrm{kg} / \mathrm{hr}$ in neonates); polydipsia, characterized by water intake of more than $2 \mathrm{~L} / \mathrm{m}^{2} / \mathrm{d}$ (or more than 5 $\mathrm{L} / \mathrm{d}$ ); and failure to thrive or growth retardation. ${ }^{1}$

The essential pathophysiology in central DI (CDI) involves a decrease in antidiuretic hormone $(\mathrm{ADH})$ secretion as a consequence of neoplasms, autoimmune pathologies, trauma, pituitary surgery, hypoxia or ischemic encephalopathy. In nephrogenic DI (NDI), despite normal ADH secretion, kidneys are refractory to the effects of $\mathrm{ADH}$. In both polydipsia and $\mathrm{DI}$, water diuresis is present. However, in water and solute diuresis, excretion of solutes increases and ADH dysfunction involving either its secretion or renal response to $\mathrm{ADH}$ develops. With its natriuretic and $\mathrm{ADH}$-antagonizing effects, atrial natriuretic peptide (ANP) should be considered in the etiology of polyuria.

Osler first described prolonged polyuria as a cause of bilateral, non-obstructive hydronephrosis in $1892 .^{2}$ Since then, excessive urine flows and extensive dilatation of the urinary tract have been most frequently documented in young children with NDI, mostly a hereditary and X-linked disease, ${ }^{3,4}$ and also in patients with $\mathrm{CDI}^{5}$ and psychogenic polydipsia. ${ }^{6}$ Apparently, persistent large urine volumes can lead to urinary bladder distension and hypertrophy with subsequent intramural obstruction of the distal ureteral segments. ${ }^{3-6}$ With time, bladder contractility is compromised, ureteric peristalsis diminishes and large residual urine volumes worsens this functional obstructive uropathy. ${ }^{7}$ Excessive polyuric syndrome rarely gives rise to non-obstructive hydronephrosis, megaureter and neurogenic bladder.

\section{Case report}

We present an 8-year- old male patient with neurogenic bladder who was receiving anticholinergic treatment and using clean intermittent self-catheterization for 4 years. His personal and family history was uneventful. His parents did not describe any urinary symptom during his first 3 years, and he suffered with polyuria and polydipsia since then. During this time, the patient complained of nocturnal enuresis and therefore was admitted to our clinic. On physical examination, his body weight $(25 \mathrm{~kg})$, height $(122 \mathrm{~cm})$, arterial blood pressure $(102 / 68 \mathrm{~mm} \mathrm{Hg})$, and pulse rate $(95 / \mathrm{min})$ were measured. His mental development was normal.

When his previous examination results were reviewed, we noted progressive hydroureteronephrosis (Fig. 1). His daily fluid intake and urine output were nearly $6000 \mathrm{cc}$ and 5000 cc, respectively. Renal function test results, serum and 


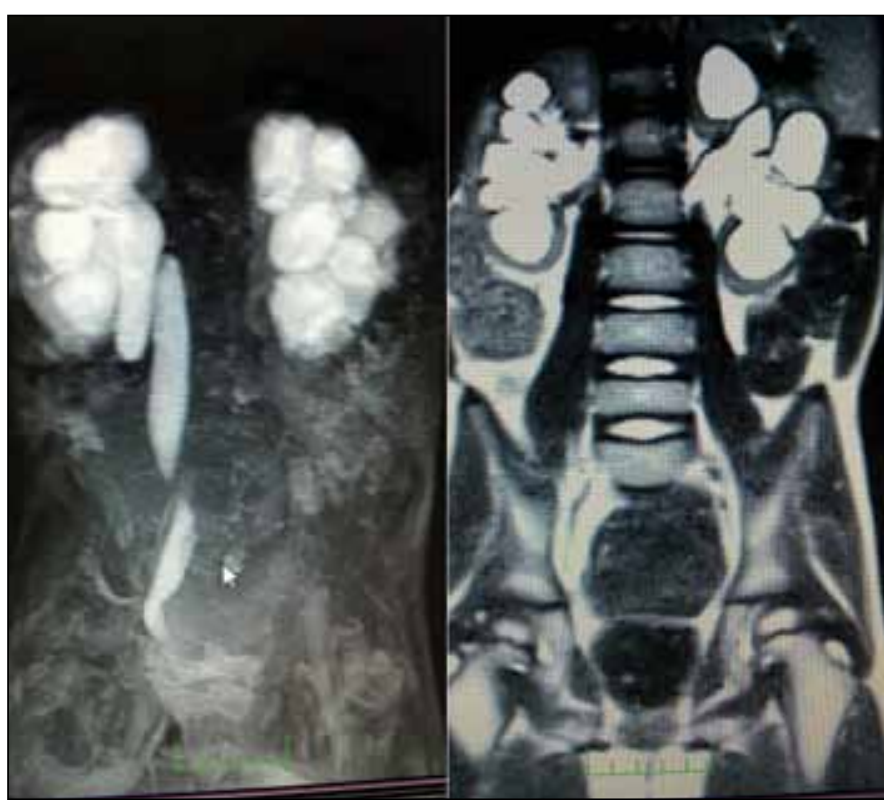

Fig. 1. Magnetic resonance urography imaging of urinary tract before 1-deamino-8- $D$-arginine vasopressin (dDAVP) treatment (left); bilateral hydroureteronephrosis (right).

urine electrolyte values were within normal limits. Urine density was 1002 . Urine and plasma osmolality measured during the early morning hours were $150 \mathrm{mOsm} / \mathrm{kg} /$ water and $310 \mathrm{mOsm} / \mathrm{kg} /$ water, respectively. The patient could not tolerate thirst. Urinary system imaging modalities revealed bilateral hydroureteronephrosis (on ultrasonograms AP diameters of the right and left renal pelvises were measured as $21 \mathrm{~mm}$ and $25 \mathrm{~mm}$, respectively), while voiding cystourethrogram demonstrated bilateral non-refluxive and nonobstructive megaureter, increased bladder capacity (350 cc), and postmictional residual urine $(250 \mathrm{cc})$. DMSA and DTPA scanning of the ureterovesical junction revealed a right and left kidney contributing $57 \%$ and $43 \%$ to total renal functions, respectively. Following diuretic injection, we detected bilateral hydroureteronephrosis with normal urine output. Urine specimens were collected for 24 hours and creatinine clearance was $39 \%$. On cystourethroscopic examination, urethra was intact, bladder was trabeculated and ureteral orifices were normal in location and configuration.

Pituitary magnetic resonance imaging (MRI) (Fig. 2) examination and analyses of cortisol, TSH and fT4 were performed to detect other potentially associated pituitary disorders, and yielded normal results. Plasma ADH level was $0.5 \mathrm{pg} / \mathrm{mL}$ (normal $\geq 1.1 \mathrm{pg} / \mathrm{mL}$ ). Thus, a diagnostic hypothesis of $\mathrm{CDI}$ was raised. A challenge test with a nasal dDVAP $10 \mu \mathrm{g}$ twice a day was performed to confirm the diagnosis of CDI. A dramatic response was obtained as early as day 2 of treatment. His daily oral fluid intake was $800 \mathrm{cc}$ and urine output was $1200 \mathrm{cc}$. Any treatment side effect was not detected.
Renal function tests, serum and urine electrolytes were controlled and evaluated as normal at 1, 3, 6, and 12 months of the treatment, respectively. At 1 month of treatment, single daily doses of nasal dDVAP were administered. Despite this change in treatment, treatment response was obtained. During follow-up, stepwise regression in hydroureteronephrosis (Fig. 3) and postmictional residual urine was observed. At 12 months post-treatment, AP diameters of the right and left renal pelvises were $7 \mathrm{~mm}$ and $8 \mathrm{~mm}$, respectively. During urodynamic examination, the patient's bladder capacity was $270 \mathrm{cc}$ with no postmictional residual urine. Urodynamic study revealed normal detrusor activity, normal bladder sensation and compliance. Renal scanning

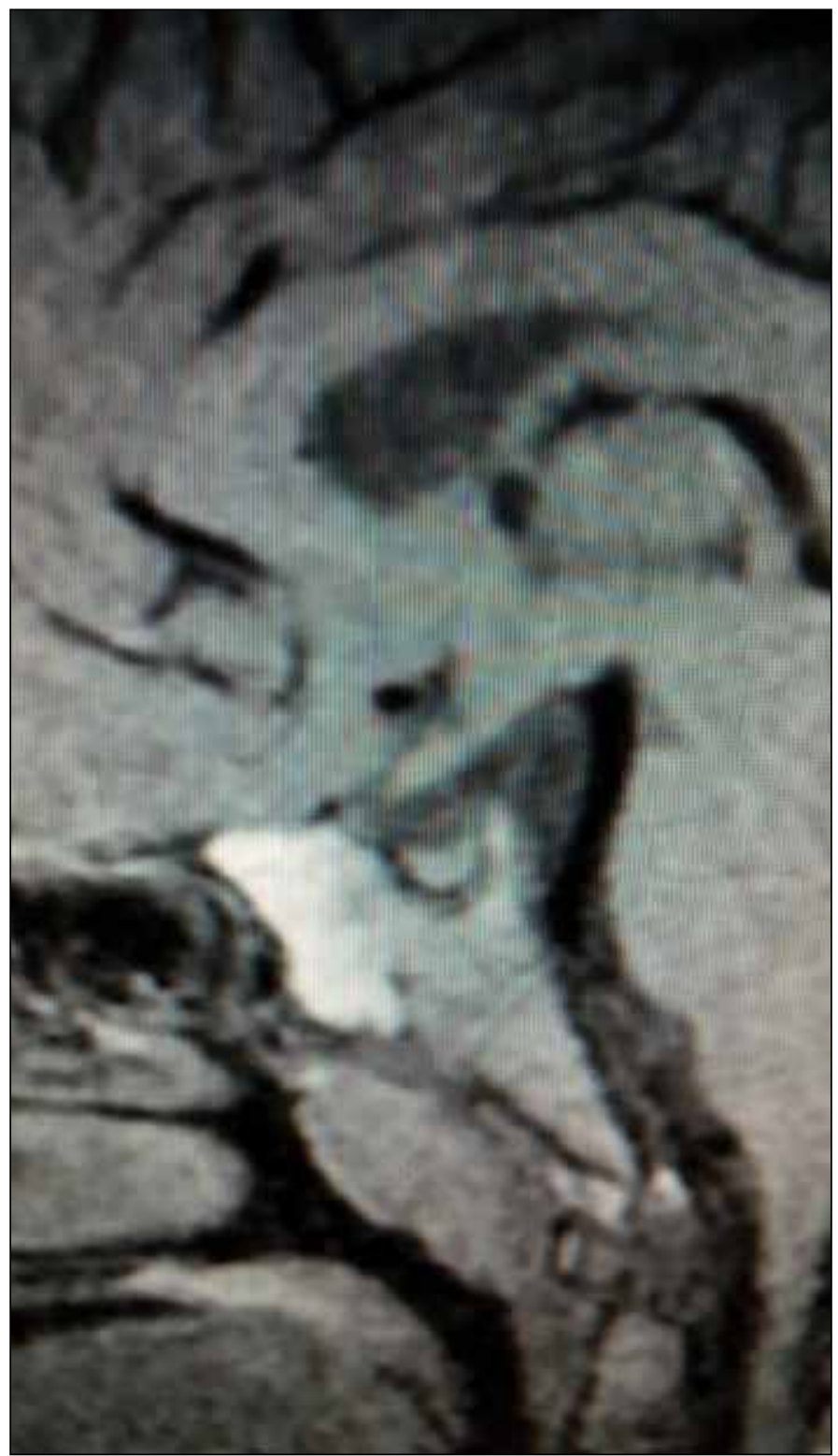

Fig. 2. Pituitary magnetic resonance image. 


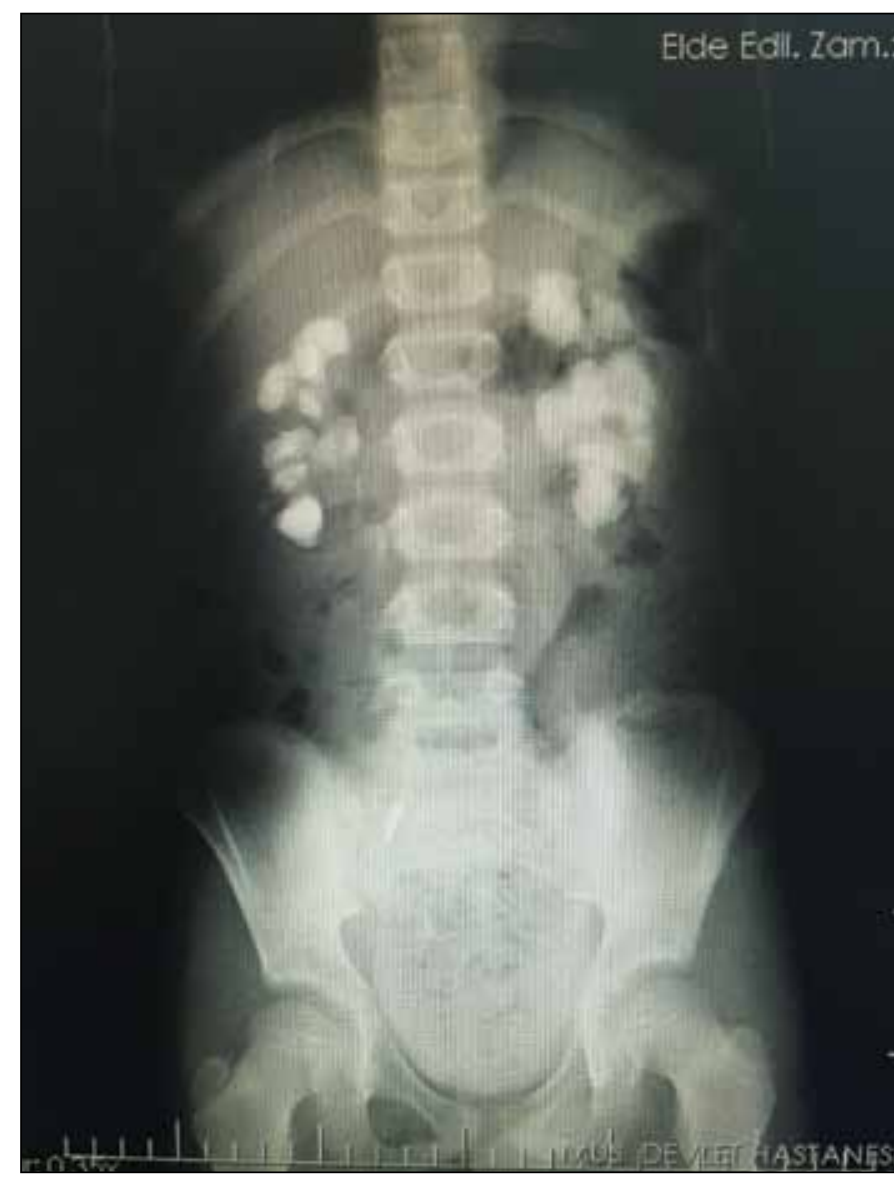

Fig. 3. Intravenous pyelography imaging of urinary tract after 1-deamino8-D-arginine vasopressin (dDAVP) treatment; regression of bilateral hydroureteronephrosis

results were not unremarkable. Presently, the patient has not required clean intermittent catheterization and treatment is maintained with single daily doses of nasal dDVAP.

\section{Discussion}

The signs and symptoms of DI vary with the etiology, loss of excessive amounts of free water, extreme feeling of thirst, dehydration and hypernatremia. Manifestations vary between age groups, depending on the patients' ability to replenish water. Younger children often manifest with primary enuresis. Older children characteristically have high urine output and nocturia leading to disturbed sleep. Familial autosomal dominant forms of CDI usually start by age 5 or 6 years, but may manifest as late as the third decade. ${ }^{8}$ Familial autosomal recessive forms manifest in infancy and the age of presentation of Wolfram syndrome, DI, diabetes mellitus, optic atrophy and deafness syndrome (DIDMOAD) may vary. ${ }^{8}$

If first urine specimen obtained in the morning has a density of 1010, then DI should be suspected. Since the urine-concentrating ability of infants is not developed fully, it is difficult to make a diagnosis based on urine density. Various studies suggest that the combination of the water deprivation test and direct ADH determination would refine the diagnosis in more than $95 \%$ of DI cases. ${ }^{9}$ A long dehydration period may provide not only an osmotic, but a volumetric stimuli. ${ }^{10}$ It has been shown that dehydration alone may induce considerable $\mathrm{ADH}$-independent urine concentration. ${ }^{11}$ Pituitary MRI is an important tool in determining CDI etiology and should always be performed after gadolinium injection to check for abnormal enhancement within the pituitary stalk. ${ }^{12}$

The therapeutic goals are primarily to reduce polyuria and decrease the feeling of thirst, so that the child is able to grow adequately and maintain a normal lifestyle. Although many patients have undergone surgical procedures to alleviate this functional obstruction, treatment should be essentially medical. ${ }^{13}$ Specific therapy depends on the etiology. Fluids alone can work in very young infants and neonates. As they have a high obligatory oral fluid intake, vasopressin therapy may cause hyponatremia. dDAVP is the current drug of choice for long-term therapy of CDI. ${ }^{14}$ This synthetic analogue has more specific antidiuretic action, negligible pressor activity and a longer half-life than the native molecule. It can be given parenteral, oral or intranasal way. Although 20 times less potent than the intranasal form, oral tablets are highly effective and safe in children with more dosing flexibility. ${ }^{15}$ The recommended doses of dDAVP are 100 to $1200 \mu \mathrm{g} /$ day in 3 divided oral doses. ${ }^{16}$ Dilutional hyponatremia, headache, hypertension and nasal congestion are some of the side effects occasionally seen.

\section{Conclusion}

In our case, dDAVP therapy reduced urine volume and led to marked radiological improvement in hydronephrosis.

Competıng interests: The authors declare no competing financial or personal interests.

This paper has been peer-reviewed.

\section{References}

1. Saborio P, Tipton GA, Chan JC. Diabetes Insipidus. Pediatr Rev 2000; 21:122-9. http://dx.doi. org/10.1542/pir.21-4-122

2. Osler W. Principles and Practice of Medicine: Designed for the use of Practitioners and Students of Medicine. D. Appelton and Co, New York; 1892.

3. Nakada T, Miyauchi T, Sumiya H, et al. Nonobstructive urinary tract dilatation in nephrogenic diabetes insipidus. Int Urol Nephrol 1990;22:419-27. http://dx.doi.org/10.1007/BF02549772

4. Uribarri J, Kaskas M. Hereditary nephrogenic diabetes insipidus and bilateral nonobstructive hydronephrosis. Nephron 1993;65:346-9. http://dx.doi.org/10.1159/000187510 
Yuksel et al.

5. Boyd $S D, \operatorname{Raz} S$, Ehrlich RM. Diabetes insipidus and nonobstructive dilatation of urinary tract. Urology 1980;16:266-9. http://dx.doi.org/10.1016/0090-4295(80)90039-4

6. Singh H, Linas SL. Compulsive water drinking in the setting of anticholinergic drug use: An unrecognized cause of chronic renal failure. Am J Kid Dis 1995;26:586-9. http://dx.doi.org/10.1016/02726386(95)90593-6

7. Streitz JM Jr, Streitz JM. Polyuric urinary tract dilatation with renal damage. J Urol 1988;139:784-5.

8. Siggaard C, Christensen JH, Corydon TJ, et al. Expression of three different mutations in arginine vasopressin gene suggests genotype-phenotype correlation in familial neurohypophyseal diabetes insipidus kindreds. Clin Endocrinol (0xf) 2005;63:207-16. http://dx.doi.org/10.1111/j.1365-2265.2005.02327.x

9. Verbalis IG. Disorders of body water homeostasis. Best Pract Res Clin Endocrinol Metab 2003;17:471-503. http://dx.doi.org/10.1016/S1521-690X(03)00049-6

10. Baylis PH, Robertson GL. Plasma vasopressin response to hypertonic saline infusion to assess posterior pituitary-function. J R Soc Med 1980;73:255-60.

11. Gellai $M$, Edwards BR, Valtin H. Urinary concentrating ability during dehydration in the absence of vasopressin. Am J Physiol 1979;237:F100-4.

12. Maghnie M, di Lorgi N, Bernasconi S. Genetic forms of central diabetes Insipidus. In: Deal C, editor. MRI in congenital Hypopituitarism. London, Rimedica; 2007:99-109.
13. Singer I, Oster JR, Fishman LM. The management of diabetes insipidus in adults. Arch Intern Med 1997;157:1293-301. http://dx.doi.org/10.1001/archinte.1997.00440330027003

14. Lam KS, Wat MS, Choi KL, et al. Pharmacokinetics, pharmacodynamics, long-term efficacy, and safety of oral 1-deamino-8-D-arginine vasopressin in adult patients with central diabetes insipidus. Br J Clin Pharmacol 1996;42:379-85. http://dx.doi.org/10.1046/i.1365-2125.1996.39914.x

15. Williams TD, Dunger DB, Lyon CC. Antidiuretic effect and pharmokinetics of oral 1-desamino-8-D-arginine vasopressin: 1. Studies in adults and children. J Clin Endocrinol Metab 1986;63:129-35. http://dx.doi. org/10.1210/icem-63-1-129

16. Muglia L, Maizoub JA. Disorders of the posterior pituitary. In: Sperling MA, editor. Pediatric Endocrinology. 3rd edition. Philadelphia: Saunders; 2008:356-73.

Correspondence: Dr. Ahmet Urkmez, Fatih Sultan Mehmet Research and Training Hospital, Department of Urology, Icerenkoy/Atasehir, Tr-34752 Istanbul, Turkey; ahmeturkmez@hotmail.com 